referencing. Compilation of a 1181 page multi-author book with these attributes is obviously the result of careful planning and detailed iterative editing. Among the topics covered are orbital evolution, collisions, regolith development, reflectance spectroscopy, mineralogy, meteorite properties, formation from the solar nebula and possibilities for exploration by spacecraft.

Reading the volume, one is impressed by the diversity of techniques used to study asteroids. For example, asteroid diameters are now determined by measurement of polarization as a function of phase angle, the ratio of optical and infrared brightness, speckle interferometry, radar and occultations. Prior to 1970 diameters could only be estimated by visual telescopic observation. The most spectacular development described is the application of accurate spectral reflectivity measurements to reveal information on surface mineralogy. The measurements, combined with crystal field theory and laboratory data, have shown that asteroids are complicated bodies with diverse physical properties and surface mineralogy. One of the challenging goals for future theories on the origin of the Solar System will be to explain how such diversity could have been produced in what probably was only a small fraction of the solar nebula. Another exciting aspect of the reflectivity work is the attempt to identify specific asteroid parent bodies for various meteorite types.

Asteroids is a comprehensive and definitive book that will be of value to a variety of readers. For the specialist it will probably be the major reference source until future developments add a major increment to existing knowledge; such an advance will possibly not occur until a multi-asteroid spacecraft mission can be flown. For the newcomer to asteroid work the book will be invaluable because it contains numerous suggestions for future research. It also contains 140 pages of tabulated data for a large number of asteroids; this remarkable compilation contains information on orbital parameters, spectral reflectances, polarimetry, radiometry, light curves, magnitudes, diameters and discovery circumstances. In addition to active researchers, Asteroids will appeal to a much wider audience because of the review nature of the contributions. To smooth the mismatches that often occur in such an interdisciplinary field, a glossary is also included.

Although this is an excellent book it does, of course, have some shortcomings. Fortunately, these are of a relatively minor nature. A mineral defined in the glossary is misspelled and a few of the glossary definitions are not well thought out. In the text some of the material on meteorites is not as comprehensive as it could have been and does not reveal to the general reader the elements of controversy that exist in certain areas. In almost all other aspects, however, Asteroids is a real gem and remarkably enough for a book of its size is inexpensive enough to be a painless addition to one's personal book collection.

D.E. Brownlee is Associate Professor of Astronomy at the University of Washington, Seattle, and Associate in Geochemistry at the California Institute of Technology, Pasadena.

\section{Children's skills with a difference}

\section{Peter Bryant}

Beyond Universals in Cognitive Development. By David Henry Feldman. Pp.204. (Ablex: New Jersey, 1980.) $\$ 17.50$

THERE is a character in Flaubert's short tale A Simple Life, who on being shown a map of America where her adopted son was at the time asked if she could see his house on the map and then if she could see him. Here is a dramatic if extreme illustration of the fact that people's skills with maps vary widely. This sort of variation between people is David Feldman's starting point and maps happen to be his main example.

His basic argument is impeccable. People's skills vary wildly. Some people play chess well, others are excellent gardeners and so on. Yet studies of the development of skills in children have concentrated on the few which virtually all adults possess. The understanding of number, the ability to make and understand logical inferences, even reading and writing are achievements which we take for granted in other adults, and yet these are at the centre of studies of child development. We spend very little time on studying how adults become so different from each other.

Feldman's approach is to look for similar variability among children, and he looks at two topics. The first is the way in which children draw maps. He divides this skill into a number of components and shows that different children forge ahead with different components. So much seems to be empirical fact. What causes this variability is still a matter for speculation, of which there is a great deal in this book.

His second example is creativity, but here because the measures of this elusive quality have been so unsuccessful Feldman's account is much less impressive. But he is right to point out that we have concentrated too much on universal features on human development and too little on the variations.

Peter Bryant is Watts Professor of Psychology at the University of Oxford.

\section{New Studies in Biology}

\section{Light and Plant Life}

J. M. Whatley and

F. R. Whatley, FRS

An overall view of the effects of light on plant growth and development, from germination and seedling establishment, to flowering and senescence.

Paper $\{3.4096$ pages

\section{Lipids and Polysaccharides in Biology} Anna J. Furth

This book describes exciting, new aspects of polysaccharide and lipid biochemistry emphasizing the range of basic medical and biological problems that could be elucidated by structure-function studies of these somewhat neglected cell components.

Paper $£ 2.6072$ pages

\section{Coming in November:}

\section{Bioenergetics of Autotrophs and Heterotrophs}

\section{John W. Anderson}

The book demonstrates that the principles of bioenergetics provide a unifying concept for understanding the metabolic activities of organisms, their interdependence and the cycling of elements by organisms.

Paper $£ 2.5064$ pages

\section{Coming in December:}

\section{Invertebrate Respiration}

\section{Rufus M. G. Wells}

In this study, invertebrates are seen not as merely 'lower' animals, but as displaying control and regulatory capabilities which must cope with greater environmental exigencies than those of the vertebrates.

Paper $£ 2.60$ approx 72 pages

\section{Immunobiology}

\section{Christopher J. Inchley}

A concise introduction to the cellular basis of immune response in man and other animals, written from a biological viewpoint.

Paper 12.75 approx 88 pages

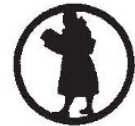

Edward Arnold 41 Bedford Square, London WC1B 3DQ 